\title{
O CORPO DA BICHA E SUAS RESSIGNIFICAÇÕES ${ }^{1}$
}

\section{EL CUERPO HOMOSEXUALY SUS RESIGNIFICACIONES}

\author{
João Batista Figueiredo de Oliveira² \\ Norma Missae Takeuti ${ }^{3}$
}

\section{RESUMO}

Este artigo traz uma reflexão sobre a construção de corpos múltiplos e sexualidades variadas, no tempo e em espaços diferenciados. Orientando-nos pela hipótese de que a sexualidade é um campo de tensões e de jogos de poderes, passamos a pensá-la como um espaço em que variadas semióticas e forças em ação tecem os desejos e compõem os jogos imagéticos daquilo que se compreende como condição sexual. Assim, as ressignificações do corpo ocorrem de acordo com os modos de reterritorialização: o deslocamento com relação a uma dada forma "original" leva à construção de novas formas e novos contornos, mais fluidos, tendo em vista a própria experimentação do

\footnotetext{
${ }^{1}$ Este artigo está baseado, em parte, na dissertação Corpos em mutações - cartografia das sexualidades nômades na Praça Mits, defendida em 29 de janeiro de 2016, por João Batista Figueredo de Oliveira, no Programa de Pós-Graduação em Ciência Sociais da Universidade Federal do Rio Grande do Norte (UFRN), sob a orientação de Norma Takeuti; e, de outra parte, em pesquisas sobre Inventividades, micropolíticas, processos de subjetivação realizadas por Norma Takeuti.

${ }^{2}$ Doutorado, mestrado e graduação (licenciatura) em Ciências Sociais pela Universidade Federal do Rio Grande do Norte (UFRN). Graduação em Turismo pela (UFRN). E-mail: jb.figueredo@ hotmail.com ${ }^{3}$ Professora Titular de (Ciências Sociaisł da Universidade Federal do Rio Grande do Norte (UFRN). Pósdoutorado na Université Paris VII7 - Denis-Diderot 2 - França. Doutorado e Mestrado em Estruturas e Mudanças Humanas nas Organizações na Université de-Paris $\underline{I^{9}} 9$ - Dauphine, França. Graduação em Administração de Empresas na Fundação Getúlio Vargas (UFGV/SP). Pesquisadora-associada do Laboratoire due Changement Social et Politique - Université Paris VIII. Líder do Grupo de Estudos Culturas e Subjetividades-Poiesis_(UFRN). E-mail: normitk@gmail.com;
} 


\section{O CORPO DA BICHA E SUAS RESSIGNIFICAÇÕES \\ João Batista Figueiredo de Oliveira \\ Norma Missae Takeuti}

movimento de desterritorialização. A partir disso, abre-se um novo campo de perspectiva e possibilidade ao próprio corpo.

Palavras-chave: Corpos. Sexualidade. Ressignificação.

\section{RESUMEN}

En este trabajo se reflexiona sobre la construcción de múltiples cuerpos y sexualidades diversas, en diferentes momentos y espacios. Se basa en la hipótesis de que la sexualidad es un campo de tensiones y de juegos de poder, para pensarla como un espacio en el que varias semióticas y fuerzas en acción tejen los deseos y componen los juegos de imágenes de la que se define como condición sexual. Así es que las resignificaciones del cuerpose dan de acuerdo con las formas de reterritorialización: el desplazamiento a una forma "original" conduce a la construcción de nuevas formas y contornos, más fluidos, teniendo en cuenta que ya hayan experimentado el movimiento de desterritorialización;y a partir de eso, presentanun nuevo campo de perspectiva y posibilidades de su propio cuerpo.

Palabrasclave: Cuerpos. Sexualidad. Resignificación.

Este artigo trata de uma reflexão sobre determinados espaços sociais em que há expressões de reconfiguração de corpos sexuais a partir de tentativas de fissuras no campo da normatividade social. A empiria mencionada, neste texto, está baseada na pesquisa intitulada Corpos em mutações e contempla alguns questionamentos feitos no texto dissertativo, mais particularmente, naqueles que dizem respeito aos mecanismos da 


\section{O CORPO DA BICHA E SUAS RESSIGNIFICAÇÕES \\ João Batista Figueiredo de Oliveira \\ Norma Missae Takeuti}

heteronormatividade, bem como às pragmáticas inventivas que emergem em determinados estratos da sociedade ${ }^{4}$.

Em que se constituem as tentativas de construção de corpos que têm como referência maior o sistema heteronormativo e quais seriam as formas de fissuras em relação a esse sistema de significação dominante? Ao formularmos essa questão, temos em mente o fato de ser característico das formações capitalistas a recorrência deum tipo particular de máquina semiótica significante que concorre na produção da subjetividade (LAZZARATO, 2014) ${ }^{5}$.

Para esta reflexão, o importante não é saber até que ponto os dispositivos da heteronormatividade são eficazes ou não; mas sim, observar como as pessoas constroem corpos múltiplos no tempo e em espaços diferenciados. Em uma mesma sociedade há variações nas formas de se experimentar, no próprio corpo, a sexualidade, e, de forma mais pontual, há modulações em um mesmo indivíduo de sua sexualidade, no percurso de sua vida. Orientando-nos pela hipótese de que a sexualidade é um campo de tensões e de jogos de poderes, passamos a pensá-la como um espaço em que variadas semióticas e forças em ação tecem os desejos e compõem os jogos imagéticos daquilo que se compreende como condição sexual. Quando uma criança nasce, ela não possui uma semiótica do desejo que possa determinar sua condição sexual. Ela se define por movimentos desarticulados, comuns a essa fase inicial da vida: emissão de sons como o choro, sucção com a boca, movimentos sem direção calculada de braços e pernas que, só aos poucos, vão configurando o corpo e elaborando um conjunto de semióticas, até desenvolver a linguagem.

No processo de tentativas de configuração do corpo na infância, a imposição da heteronormatividade será uma dinâmica constante. No seio materno e no regaço do pai, a criança aprenderá a "ser" heterossexual. A toda

\footnotetext{
${ }^{4}$ Esta é a proposta da linha de pesquisa que orienta os trabalhos dos pesquisadores do Grupo de Estudos Culturas e Subjetividades - Poiesis/UFRN.

${ }^{5} \mathrm{Na}$ obra Signos, máquinas, subjetividades, o autor decortica a teoria semiótica de Félix Guattari para abrir a compreensão da produção de subjetividade contemporânea.
} 
transgressão em relação aos códigos instituídos, há sanções sociais previstas (castigos) de caráter tanto físicos quanto simbólicos para que não haja desvios dos papéis sexuais definidos nas normas sociais. Bento (2011) radicaliza a crítica à sanção imposta socialmente sob o termo heteroterrorismo:

\begin{abstract}
As reiterações que produzem os gêneros e a heterossexualidade são marcadas por um terrorismo contínuo. Há um heteroterrorismo a cada enunciado que incentiva ou inibe comportamentos, a cada insulto ou piada homofóbica. Se um menino gosta de brincar de boneca, os heteroterroristas afirmarão: "Pare com isso! Isso não é coisa de menino!". A cada reiteração do/a pai/mãe ou professor/a, a cada "menino não chora!", "comporta-se como menina!", "isso é coisa de bicha!", a subjetividade daquele que é o objeto dessas reiterações é minada. (BENTO, 2011, p. 552)
\end{abstract}

Os pais, em conjunto com a sociedade, exercem a função de modelamento dos corpos das crianças, de modo que elas se tornem "naturalmente" heterossexuais a partir de um tipo ideal de heterossexualidade.

São várias as instâncias sociais que revestem os corpos de significados- semióticas de significação, conforme Lazzarato (2014) - e cada parte terá um nome, uma função e um conjunto de simbologia sobre ela. Trabalho de modelação feito, passo a passo, em uma dinâmica que se denomina de pedagogia da sexualidade ${ }^{6}$, para ensinar/adestrar como é que deve se expressar o desejo sexual das pessoas, tudo sendo monitorado para que não haja desvios. Assim, a criança será ensinada a seguir os papéis e os significados atribuídos pela heteronormatividade.

O corpo é submetido às tentativas de configurações por processos que atravessam a carne do sujeito - impregnando-se em sua forma de sentir seus afetos e desejos -, muito embora todos esses processos (de impregnação) não sejam percebidos na medida em que há uma naturalização das sexualidades.

Várias forças formam os corpos sexuais (até mesmo, relativamente, aos agora chamados assexuais), que não se limitam ao campo da linguagem;

\footnotetext{
${ }^{6}$ Apenas relembrando que, em História da sexualidade: a vontade de saber, volume 1 (FOUCAULT, 1980), encontramos uma exemplar problematização dessa "pedagogia".
} 


\section{O CORPO DA BICHA E SUAS RESSIGNIFICAÇÕES \\ João Batista Figueiredo de Oliveira \\ Norma Missae Takeuti}

forças outras - semióticas a-significantes, conforme Lazzarato (2014) - que também compõem o campo da afetividade, dos sentimentos e das sensações vivenciados pelo corpo. Os múltiplos corpos não são apenas racionalidades, são sensações, desejos e anseios.

Como, então, é possível, com todos esses dispositivos disciplinares ${ }^{7}$ que buscam moldar os corpos, emergirem outras pragmáticas sexuais, chamadas "desviantes" ou "anômalas"? Ora, podemos refletir sobre essa questão observando a própria construção dos dispositivos de configuração de corpos heterossexuais. Se esses dispositivos são construídos, eles podem ou não funcionar.

Para compreender melhor essa possibilidade de não funcionamento de um processo de moldagem de corpos, tão organizado e compactuado socialmente para a produção de heterossexuais-padronizados, podemos lançar mão às noções de Rolnik (2006), as quais ajudam a pensar essa possibilidade de desvio. Pensemos no exemplo trazido pela autora a respeito da mídia como forte ferramenta de captura das subjetividades que também produz outro efeito: o da possibilidade de outros agenciamentos atuarem por meio de imagens, cores e movimentos. Com os dispositivos de configuração de corpos ocorre o mesmo: eles são potencialmente cheios de brechas que possibilitam outras experimentações, a partir mesmo do próprio contato da criança com o mundo. Aqui, mundo não deve significar só aquilo que se entende por sociedade humana; mas sim a natureza como um todo - animais, plantas, vento, nuvens, batom da mãe, chapéu do pai, perfumes etc. - todos esses elementos que possibilitam à criança se colocar em meio a outros agenciamentos. Se, por um lado, existe toda uma força normativa sendo trabalhada; por outro, o devir da vida permite uma multiplicidade de experimentações, sobre as quais as normas de sexualidade não possuem um alcance, em sua totalidade.

\footnotetext{
${ }^{7}$ Fazemos alusão às análises de Foucault sobre a genealogia do poder.
} 


\section{O CORPO DA BICHA E SUAS RESSIGNIFICAÇÕES \\ João Batista Figueiredo de Oliveira \\ Norma Missae Takeuti}

Se abordarmos o corpo na perspectiva proposta por Deleuze e Guattari (2012), diríamos que nele nada se encontra concluído - nem nos corpos e tampouco na realidade em geral -, pois, pelas modulações possíveis, o que existe é um movimento constante de transmutação. Portanto, se as modulações são constantes, é compreensível entender que uma forma de configuração, que pretende moldar corpos, pode, a qualquer momento, falhar; basta um elemento qualquer, despercebido ou rebelde, penetrar no campo da multiplicidade de formação dos corpos, e o resultado temporário (levando em conta o movimento constante de modulação) será outro.

Desse modo, podemos dizer que os corpos mutantes são aqueles que agenciarão as novas formas de se estar (propositalmente não usamos o verbo ser) pela possibilidade aberta pelas brechas que se produzem no campo da normalização das sexualidades. Os corpos se valem das fissuras dos tecidos normativos para se instalarem nas linhas de fuga (DELEUZE; GUATTARI, 2012). Todavia, os processos - pelos quais os corpos realizam mutações e anomalias $^{8}$ de encontro às normas - são complexos, trata-se de uma diversidade de formas e de situações contextuais particulares a cada pessoa. A título de exemplo, esbocemos um percurso possível de uma criança submetida à territorialidade heteronormativa: aí existem, ainda assim, afetações não previstas permitindo-lhe desenvolver vontades, sensações e sentimentos não convergentes com os códigos impostos. Essa criança, geralmente, irá se encontrar em embates diante da exigência de adequação aos códigos normativos, entretanto, ao se produzir algum elemento imprevisível lançando-a a algum tipo de novo agenciamento, ela poderá seguir o rumo da negação dos desejos anômalos ou o rumo da mutação.

Outro aspecto para analisarmos as transgressões são as fissuras. Um corpo fissurado seria aquele que, mesmo com toda a força existente no conjunto de códigos da heteronormatividade, consegue produzir um tipo de

\footnotetext{
${ }^{8}$ Anomalias pensadas, na esteira dos autores citados, como algo imprescindível para a expansão da vida.
} 


\section{O CORPO DA BICHA E SUAS RESSIGNIFICAÇÕES \\ João Batista Figueiredo de Oliveira \\ Norma Missae Takeuti}

vontade, sensação e sentimento que leva uma pessoa a viver, primeiramente, a angústia da anomalia; contudo, é essa mesma angústia força motriz de um trabalho de reconstrução de perspectivas, moralidades e, sobretudo, de produção de novos sentidos para si enquanto corpo. Na hipótese de ausência da angústia ${ }^{9}$, todo o corpo deslocado da configuração hegemônica se fará sempre por meio de um trabalho de ressignificação de si. Essas novas formas de significações apresentam uma ampla escala de variação. A fissura em si já é uma forma de significação diferente. Convém frisar que mesmo os corpos configurados hegemonicamente experimentam, de alguma forma, transformações, pois, por mais moldados que pareçam, também estão afeitos a modulações imperceptíveis que podem (ou não) resultar em mudança de perspectivas maiores.

A propósito das ressignificações do corpo, compreendemos que são formas de reterritorialização (DELEUZE;GUATTARI, 2012) e que o deslocamento da forma dada leva à construção de novas formas e novos contornos agora mais fluidos, tendo em vista que já se experimentou o movimento de desterritorialização e sendo que a partir dele pode-se abrir um novo campo de perspectiva e possibilidade ao próprio corpo(ESCÓSSIA; TEDESCO, 2009).

Pensemos no ânus como exemplo de órgão ressignificado. Existe um discurso bastante antigo e difundido de que o ânus é apenas um órgão excretor. Sobre isso, Preciado (2009) resgata toda uma problematização denominada castração anal, na qual o ânus é relegado ao esquecimento. A autora relembra-nos o papel da religião e de campos de moralidades no desenvolvimento de estratégias de imposição relacionadas a qualquer prática erógena com o ânus, pontuando a significação de imoralidade e de imundice de tal forma que a sua função esteja exclusivamente orientada para a defecação. O seu argumento é de que, mesmo diante de toda essa carga

\footnotetext{
${ }^{9}$ Muito embora esse tipo de sentimento de angústia é quase sempre incontornável em sociedades normativas.
} 
O CORPO DA BICHA E SUAS RESSIGNIFICAÇÕES

João Batista Figueiredo de Oliveira

Norma Missae Takeuti

moral histórica, as pessoas cujas sexualidades são consideradas socialmente desviantes conseguem ressignificar o ânus, dando-lhe (ou devolvendo-lhe) uma importante função no erotismo sexual.

Inclusive, as bichas ${ }^{10}$ introduzem desvios na linguagem para significar o ato da penetração anal, por exemplo, o termo "cuceta" ou, ainda, "chuca", que seria uma "técnica" de cuidados do ânus e assim por diante. Ocorre aí um movimento que não se reduz à técnica de uso do corpo pelo sujeito; mas há a proposição para uma semiótica renovada nos desdobramentos das mutações do corpo. Do movimento coletivo de troca de ideias e noções entre bichas - a partir do qual são feitas articulações sobre as possibilidades do corpo - a uma espécie de concretização de posturas políticas (corpo-política) ${ }^{11}$. A penetração anal não seria, então, um simples ato de prazer ${ }^{12}$, seria um ato político que viria contrariar normas e simbolismos e que viria quebrar códigos instituídos e (quiçá!) liberar, a partir do corpo, forças inventivas em uma sociedade normalizada. Seria um ato simbólico de arrombamento de si, possibilitando um corpo em mutação, um devir-corpo.

Importante deixar registrado as tensões do próprio raciocínio que enfatiza a bicha potência política, isto é, as tensões que resultam, de um lado, pelo conhecimento das formas de ressignificação e, de outro, pelo conhecimento da existência de reafirmações de elementos heteronormativos no interior do dito campo LGBTI. Porém, mais do que fazer um debate cotejando cada latitude, a nossa opção recai em discutir as condições de possibilidade de abertura a agenciamentos que vêm alargar o espectro das expressividades dos corpos e das sexualidades na perspectiva de ampliação

\footnotetext{
${ }^{10}$ O termo "bicha" é a forma como os jovens, em nossa pesquisa, comumente se interpelam. Ocorre, aí, uma espécie de "giro semântico": o termo outrora utilizado para menosprezar as homossexualidades é, agora, resgatado com despojamento para se autodenominar e nominar o outro com quem compartilha uma estética da subversão.

${ }^{11}$ No texto Multidões queer, Preciado (2011) desenvolve a noção sexopolítica para refletir as políticas do corpo (corpo-política), compreendendo as formas de significados que são impostas aos corpos e as vias de transgressões.

12 Ou uma "perversão", como é comumente definida em uma sociedade normalizada.
} 
O CORPO DA BICHA E SUAS RESSIGNIFICAÇÕES

João Batista Figueiredo de Oliveira

Norma Missae Takeuti

de mais espaços lisos ${ }^{13}$ na sociedade nos quais os fluxos desejantes não encontrem bloqueios e impasses.

Como a bicha como xingamento foi agenciada e transformada na bicha potência política? Pensemos na bicha enquanto uma figura conceitual- noção trazida por Deleuze (2006) -, ela teria, em si, os diversos elementos de potencialidades subversivas em uma multiplicidade de máscaras. Estas foram sendo construídas, experimentadas e ressignificadas no tempo e no espaço. Do estereótipo de bicha - que foi desenhado pela sociedade ocidental e que foi apropriado por grande parte da comunidade homossexual - até ganhar novos significados. Pensemos, então, nesse deslocamento e nessa agitação (não só de ordem semântica) até se tornar um "recurso" político. Isto é, a bicha estaria criando, no corpo, a marca da transgressão, que se faz perceptível como uma postura política, com possíveis produções de fissuras sociais. É nisso em que se constitui a desterritorialização da bicha: de agenciada à agenciadora, ela seria mais do que uma figura empírica. É uma figura conceitual!

As homossexualidades na história são permeadas por vias inventivas. $O$ mudar de pele, igual às serpentes, sempre foi necessário para um público que ou se conformava com o corpo-político vigente, ou inventava novas formas de viver seus desejos. Para não ficarmos em uma abstração, traremos um exemplo concreto de uma figura conceitual: Madame Satã ${ }^{14}$.

Na primeira metade do século XX, surge Madame Satã (João Francisco dos Santos) ${ }^{15}$ no Rio de Janeiro, com seus passos de capoeira driblando as normas. Sua pele, seus lábios e seu rosto eram expressões da subversão necessária para a construção do novo. Madame Satã era louca, desregrada e sua voz assustava a audição codificada da sociedade da qual fez parte e que, ao mesmo tempo, transcendeu quando se projetou à frente, não para viver uma fantasia ou uma esquizofrenia, mas para violentar as estruturas imaculadas de

\footnotetext{
${ }^{13}$ Fazemos alusão ao texto O liso e o estriado de Deleuze e Guattari (1997).

${ }^{14} \mathrm{~A}$ sua apresentação só pode se dar em um tom mais ensaístico.

${ }^{15}$ A Revista Memória LGBT trouxe em sua edição n. 1 a vida de Madame Satã. Disponível em: <https://goo.g1/RGrcQ2>. Acesso em: 10 jan. 2017.
} 


\section{O CORPO DA BICHA E SUAS RESSIGNIFICAÇÕES \\ João Batista Figueiredo de Oliveira \\ Norma Missae Takeuti}

sua época. Seu desejo estava em pleno fervilhar, seu corpo era cartaz, venenoso, uma assombração para as sentinelas das morais e dos bons costumes.

Madame Satã era corrompida, sujava as realidades tão bem estruturadas para conter as possibilidades do desejo. Mas o desejo é como óleo, escorre pelas brechas, vaza, desliza e vai se movimentando em um corpo, em vários corpos e, por fim, no coletivo. O desejo é louco para com as regras aprisionadoras, mas é ético para com a expansão da vida (assim falando no tom dos autores que nos inspiram nas pesquisas: Deleuze e Guattari). O desejo de Madame Satã era trans, transposto a corpos localizados, aprisionados e atravessados pela norma cisgênero. Ela só tentou experimentar espaços de expressões em seu corpo negro e fez dele argila nas mãos do oleiro desejo, que se movimentava agitado. Seu corpo era grito por liberdade das diferenças sexuais/afetivas. Seu corpo era teoria para uma época em que ainda não haviam explodido as manifestações sexuais; era poesia que iniciava um movimento de pressão estética e ética contra as cadeias que tentavam, a qualquer custo, colocar-se nos "sodomitas, pederastas, invertidos, efeminados, desregrados e bestiais", que nada mais eram do que expressões do desejo mutante; nada mais eram do que o desejo escorregando pelas brechas e rachaduras das estruturas cis/heteronormativas.

O corpo de Madame Satã era a fluidez da subjetividade, o grito que exclamava: não há gênero natural, há vestimenta de gênero; não há identidade masculina ou feminina, há possibilidades múltiplas. Ela era "homem vestido de mulher", assim diriam os cis; era "transtornada", diriam as ciências de sua época; "possessa", diriam os religiosos; uma "bandida" (a sua bandidagem era usar o corpo de forma adulterada). Não! Madame Satã só modulou seu corpo, vestiu o gênero que quis, seu pênis não dava sinais para seu corpo de masculinidade, seu pênis era pênis de mulher. Pois, o pênis pode ser de homens ou de mulheres, ou de homem-mulher, ou de pessoa, só pessoa, nem homem e nem mulher. O pênis não é masculino ou feminino, assim como todo o corpo não o é, o pênis é só um músculo. O masculino, o feminino, o 


\section{O CORPO DA BICHA E SUAS RESSIGNIFICAÇÕES \\ João Batista Figueiredo de Oliveira \\ Norma Missae Takeuti}

andrógino, a pessoa não binária são vestimentas, configurações de conexões, não há nada fixo e nada natural, pois as configurações das conexões mudam a cada elemento que se agrega à teia. Mesmo na binaridade, feminilidade e masculinidade modificam-se.

Madame Satã modulou seu corpo, devendo ser homem e heterossexual pelo sistema cis, permitiu-se um devir. Sendo nada pelo sistema do desejo, abriu-se às maquinações necessárias para fazer de seu corpo uma fluida performance de conexões e, a partir disso, rasgar o espaço cristalizado pelas normas e, assim, criar novos mundos.

Ela é um dos símbolos, talvez não do ativismo gay (que vai se desenrolar na primeira metade do século XX), mas das bichas-loucas presentes e ocultadas na história. Ela é símbolo das múltiplas máscaras que podemos colocar. Falamos de ativismo gay no Ocidente, pois sabemos que outros mundos vivenciaram de forma diferente e em tempos diferentes suas experiências de não heteronormatividade.

Hoje, Madame Satã está na mídia, nas telas dos computadores, foi projetada nos cinemas, é figura tolerada, assim como as atuais figuras das homossexualidades são toleradas em determinadas partes da sociedade. Figuras, portanto, conceituais que introduzem sutilmente o movimento de rasgo da heteronormatividade (mesmo que haja dimensões de captura) e, provavelmente, estreiem um movimento gerador de formas que superam as convenções de identidades dando passagem aos fluxos desejantes - a este movimento chamamos de expressões desejantes, inspirados em Deleuze e Guattari.

Madame Satã está presente em tantos lugares $^{16}$, em moléculas atravessadas nas falas, movimentos e giros. Não está inteira em um corpo,

\footnotetext{
${ }^{16}$ Para ajudar na reflexão/experimentação, sobre Madame Satã, segue um trecho da poesia de Paulo Augusto, intituladaBalada para Madame Satãa:"Madame Satã,/acabaram de me contar/que você andou por aqui./Não forneceram detalhes,/mas eu imagino./Gostaria de saber de ti:/possuías algum cãozinho,/ cativo, para alimentar?/Havia o teu, particular,/que afagavas e, modorrento,/botavas para dormir cheiroso?.../Sim - madame divina!/Eu penso./Precursora, poderosa,/lampião do asfalto./A lapa tremiacontigo,/trepava./Pelo menos ficou uma certeza:/ vão demolir toda a Lapa,/mas teu nome vai ficar,/
} 
O CORPO DA BICHA E SUAS RESSIGNIFICAÇÕES

João Batista Figueiredo de Oliveira

Norma Missae Takeuti

como possuidora, mas se pulverizou no ar em partículas de cores, sons e luzes... não possui, não captura; conecta-se gerando não mais a si como Madame Satã, mas gerando múltiplas máscaras.

\section{REFERÊNCIAS}

BENTO, Berenice. Na escola se aprende que a diferença faz a diferença. Revista Estudos Feministas, Florianópolis, v.19, n.2, p. 548-559, ago. 2011.

DELEUZE, Gilles. O pensamento nômade. In: A ilha deserta. São Paulo: lluminuras, 2006.

DELEUZE, Gilles; GUATTARI, Félix. Tratado de Nomadologia: o liso e o estriado. In: Mil platôs: capitalismo e esquizofrenia. Tradução de Peter Pál Pelbart e Janice Caiafa. São Paulo: Editora 34, 1997. v. 5.

Micropolítica e segmentaridade. In: Mil platôs: capitalismo e esquizofrenia. Tradução de Aurélio Guerra Neto, Ana Lúcia de Oliveira, Lúcia Cláudia Leão e Suely Rolnik. São Paulo: Editora 34, 2012.v. 3.

ESCÓSSIA, Liliana; TEDESCO, Silvia. O coletivo de forças como plano de experiência cartográfica. In: PASSOS, Eduardo; KASTRUP, Virgínia; ESCÓSSIA, Liliana (Org.). Pistas do método da cartografia: pesquisaintervenção e produção de subjetividade. Porto Alegre: Sulina, 2009.

FOUCAULT, Michel. História da sexualidade: a vontade de saber.3. ed. Rio de Janeiro: Graal, 1980.v. 1.

Microfísica do poder. 24. ed. São Paulo: Graal, 2007.

LAZZARATO, Maurizio. Signos, máquinas, subjetividades. São Paulo: Sesc/SP; N-1,2014.

enorme - suspenso no ar./Bojudo, grave,/prenhe de emoção e de glória."Disponível em: <https://goo.gl/kXgCNe>. Acesso: 13 out. 2014 


\section{O CORPO DA BICHA E SUAS RESSIGNIFICAÇÕES \\ João Batista Figueiredo de Oliveira \\ Norma Missae Takeuti}

PRECIADO, Beatriz. Terror anal. In: HOCQUENGHEM, Guy. El deseo homosexual. España: Melusina, 2009.

- Multidões queer: notas para uma política dos "anormais". Revista

Estudos Feministas, Florianópolis, v. 19, n. 1, p. 11-20,jan. 2011.

ROLNIK, Suely. Cartografia sentimental: transformações contemporâneas do desejo. Porto Alegre: Sulina, 2006. 